\title{
1. Why did we start with electricity markets in Europe?
}

\section{Leonardo Meeus with Valerie Reif}

In this chapter we answer three questions. First, what was the political process that led to electricity markets in Europe? Second, what were the technical drivers for creating a European power system? Third, what do we know about the benefits of integrating electricity markets in Europe?

\subsection{WHAT WAS THE POLITICAL PROCESS THAT LED TO ELECTRICITY MARKETS IN EUROPE?}

From a political perspective, the integration of electricity markets followed three main steps, with increasing levels of detail: European treaties, EU legislative energy packages and more detailed market rules that have been developed in the process of creating EU electricity network codes and guidelines.

First are the European treaties. The aim to create a common market to eliminate trade barriers between Member States dates back to the founding Treaty of Rome in 1957. Twenty-nine years later, the Single European Act of 1986 was adopted as the first major revision of the Treaty of Rome. It paved the way for what was to become one of the main achievements of the European project: the Single European Act required the adoption of measures with the aim of establishing an internal market by 31 December $1992 .{ }^{1}$ Later that year, the Council (1986) adopted energy policy objectives for the European Community, among which was that of ' $g r e a t e r$ integration, free from barriers to trade, of the internal energy market with a view to improving security of supply, reducing costs and improving economic competitiveness'. In 1988, the Commission of the European Communities published the first document on the internal energy market, which assessed that there were still considerable barriers to trade in energy products within the Community (EC 1988). On 1 January 1993, the European Single Market became a reality for the 12 Member States at that time. However, integrating the energy sector into the European Single Market alongside other goods proved lengthier and more complex than had originally been anticipated. The year 1993 turned out to be only the starting point of a long, and still ongoing, process to build an EU internal market for electricity, as we will show in this book. One reason was the legacy structure of the energy sector and the non-existence of markets at the national level. Up to the mid-1990s, the electricity sector was still dominated by state-owned or state-controlled vertically integrated utilities with regional or national monopolies. Cross-border trade was limited due to a lack of infrastructure and rules to organize this trade. 


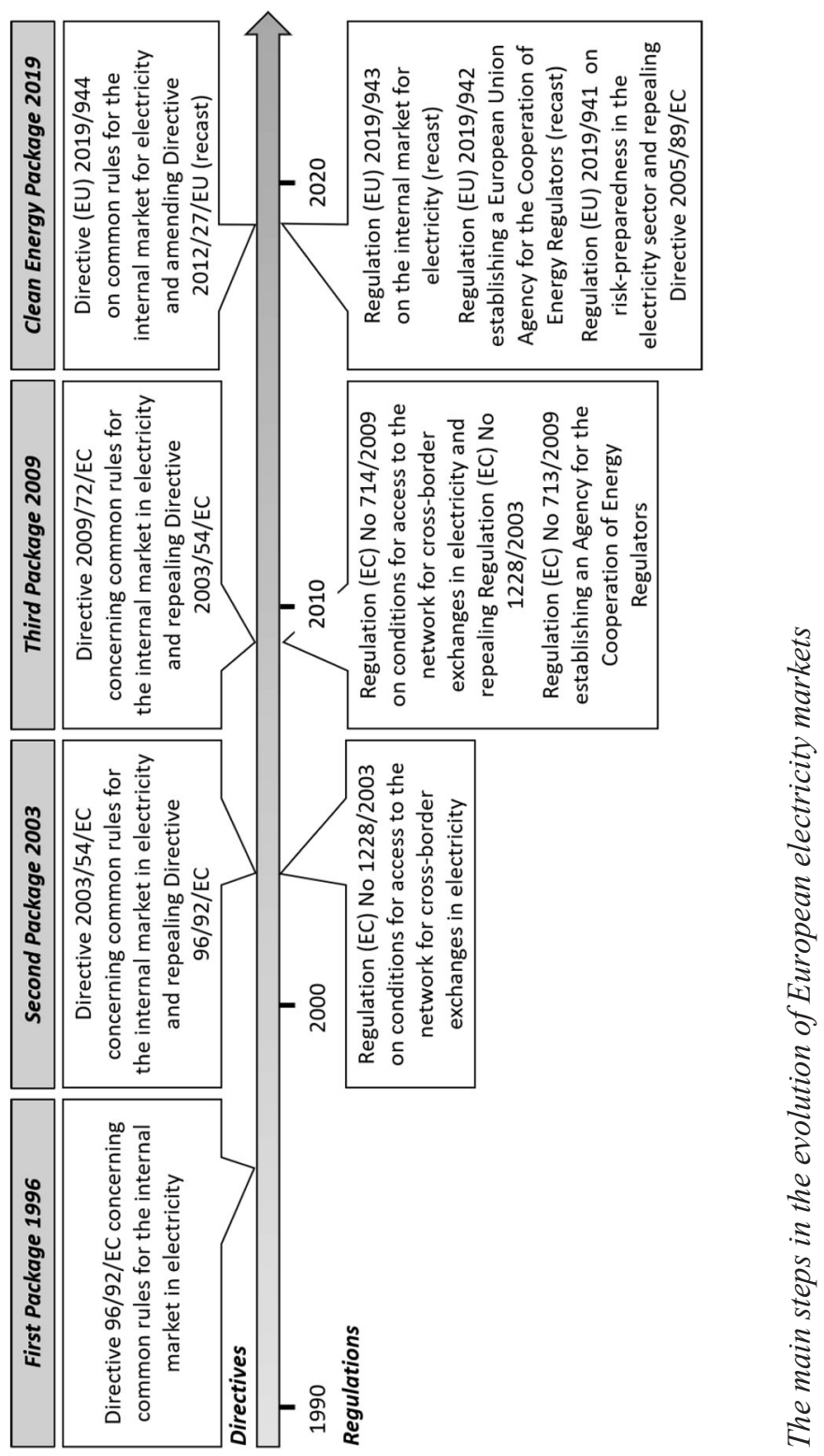

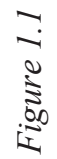


Second are the EU legislative energy packages. Profound changes were introduced to the national electricity sectors in three Electricity Market Directives in 1996, 2003 and 2009, as is shown in Figure 1.1. More recently, a fourth directive was adopted in 2019. All the directives are part of a so-called energy package. While the first three packages included one directive each for the electricity and the gas sectors plus a varying number of regulations for both sectors, the Clean Energy for All Europeans Package (Clean Energy Package, CEP) did not address the gas sector directly. Curiously enough, the naming of these packages follows its own logic, as is described in Box 1.1.

\section{BOX 1.1 NICKNAMING EU LEGISLATION}

Over the years, we have made an interesting observation regarding the naming of EU directives and regulations in the electricity sector.

Almost all the pieces of legislation have received nicknames that are widely applied. As a result of this practice, nobody remembers any of the official numbers of the regulations. In other words, Directive 96/92/EC is known as the First Directive, Directive 2003/54/EC as the Second Directive and so forth. One exception is Regulation 1228, where the number became the nickname.

It should also be noted that the development of nicknames lacked consistency and logic. Prior to the third package becoming the Third Package, it was called the Two Plus Package for a short while. This was to imply that the resulting package would merely consist of light amendments to the Second Package rather than a new package, which it turned out to be in the end. In the case of the latest package, several nicknames existed, such as Fourth Package, 2030 Package and Jumbo Package. After a brief period of Winter Package, the winner that finally emerged was Clean Energy Package.

Perhaps you are wondering why we even mention these nicknames. The reason is that if you want to become part of the industry the importance of speaking its language should not be underestimated.

The First Package and Directive 96/92/EC (First Directive) kicked off the liberalization process by introducing a distinction between the regulated part of the sector (network) and the competitive parts (generation and supply). However, it left a large margin of choice for the Member States as to how to introduce more competition into their electricity markets, resulting in significant differences in the level of market opening. Despite its failure to deliver the degree of liberalization originally intended, the First Directive gave the Member States and their national utility champions a taste of what was to come. ${ }^{2}$ In the following decades, national markets were gradually opened with the Second, the Third and the Clean Energy Package entering into force. As we will refer to the changes brought by the CEP throughout this book, Box 1.2 provides an introduction to it. 


\section{BOX 1.2 THE EU CLEAN ENERGY PACKAGE}

The Clean Energy Package is the latest of four packages that have been introducing fundamental changes to national electricity sectors since the 1990s. The CEP development process aimed to push forward the energy transition that started with the publication of draft legislative texts by the European Commission in November 2016. In June 2019, the adoption process was completed following the publication of the final legislative texts in the Official Journal of the European Union. The CEP consists of four directives and four regulations, which are listed below.

The regulations are Regulation (EU) 2018/1999 or 'Regulation on the Governance of the Energy Union', published on 21 December 2018; Regulation (EU) 2019/941 or 'Regulation on Risk-Preparedness', published on 14 June 2019; Regulation (EU) 2019/942 or the '(Recast of the) ACER Regulation', published on 14 June 2019; and Regulation (EU) 2019/943 or the '(Recast of the) Electricity Regulation', published on 14 June 2019.

The directives are Directive (EU) 2018/844 or the 'Energy Performance in Buildings Directive', published on 19 June 2018; Directive (EU) 2018/2001 or the 'Renewable Energy Directive (RED II)', published on 21 December 2018; Directive (EU) 2018/2002 or the 'Energy Efficiency Directive', published on 21 December 2018; and Directive (EU) 2019/944 or the '(Recast of the) Electricity Directive', published on 14 June 2019.

Regulation (EU) 2019/943 and Directive (EU) 2019/944 are the ones of most importance in the developments described in this book. The date of application of Regulation (EU) 2019/943 is 1 January 2020. Member States have 18 months to transpose Directive (EU) 2019/944 into national law. The European Commission will review the implementation of Directive (EU) 2019/944 and Regulation (EU) 2019/943 by 31 December 2025 and 31 December 2030 respectively. The Commission will submit a report to the European Parliament and the Council, accompanied by legislative proposals where appropriate.

Note that a major part of the early legislation focused on setting the conditions and creating the institutions necessary for electricity markets to function, but not on the actual market design or detailed market rules. In what follows, we illustrate this for transmission system operators (TSOs) and national regulatory authorities (NRAs).

As is illustrated in Figure 1.2, TSOs have been gradually made more independent from generation, which is referred to as the unbundling process. The First Package only required management and accounting unbundling. The Second Package took unbundling a step further in requiring transmission and distribution companies to apply legal unbundling from 1 July 2004 and 1 July 2007 respectively. The Third Package finally provided that as of 3 March 2012 TSOs had to be certified by the competent NRA under one of the three unbundling models: full Ownership Unbundling; Independent System Operator; and Independent Transmission Operator. Ownership unbundling emerged as the dominant model in Europe. ${ }^{3}$ The Third Package also required all the TSOs to create the European Network of Transmission System Operators for Electricity (ENTSO-E) and to cooperate through this new institution at the European level. Figure 1.2 lists some of the TSOs' and ENTSO-E's tasks, which have clearly been increasing with each legislative package that has been adopted. We do not discuss them here, as they will be covered in the various chapters of this book. The Clean Energy Package also requires the establishment of an entity of distribution system operators in the Union (EU 


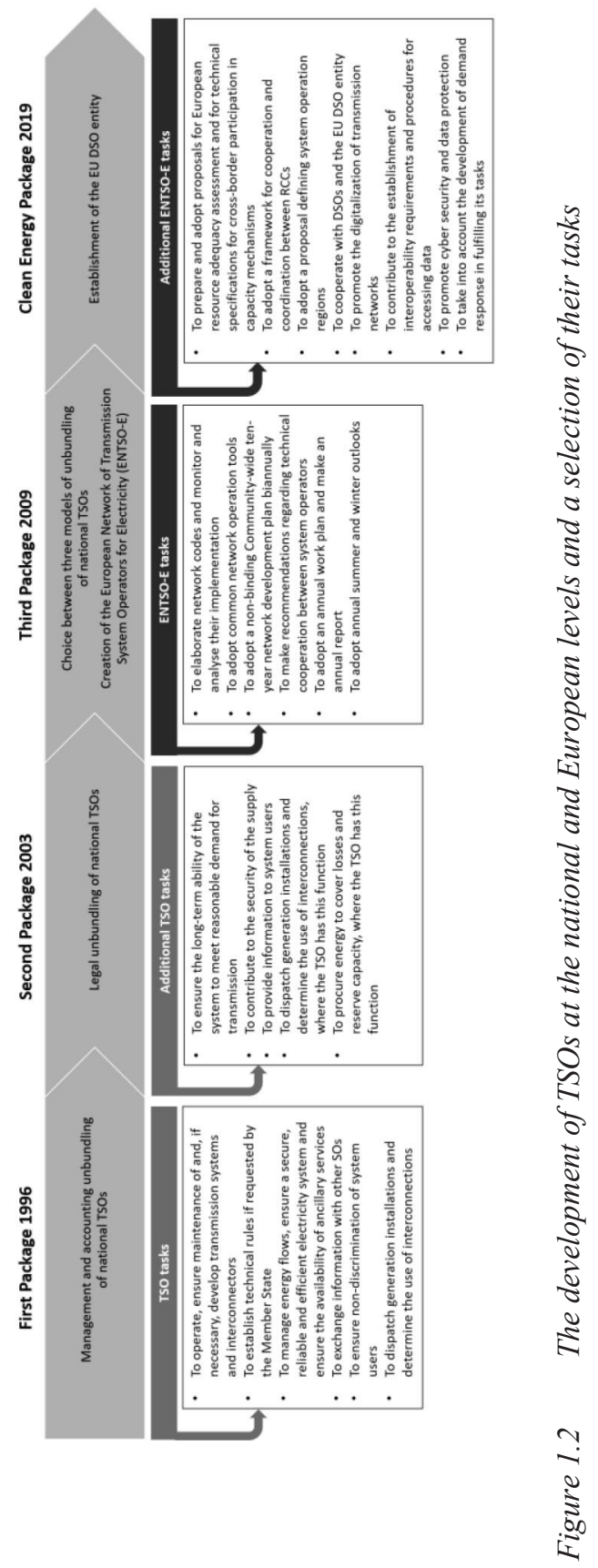




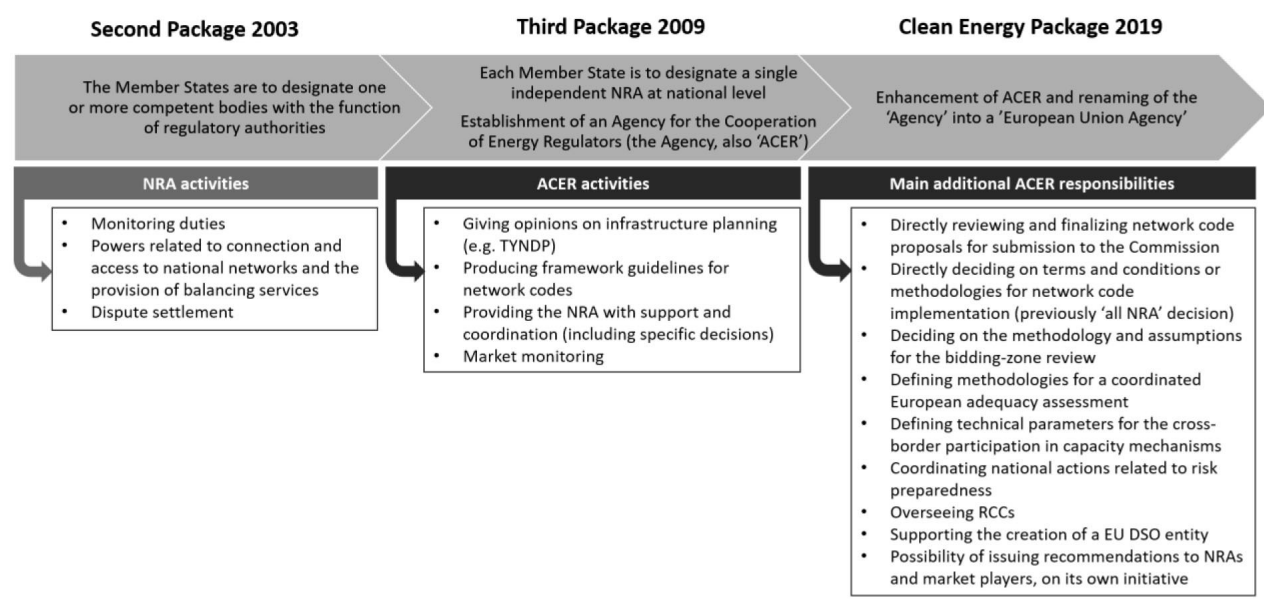

Figure 1.3 The development of regulatory authorities at the national and European levels and a selection of their tasks

DSO entity) to increase efficiencies in the electricity distribution networks and to ensure close cooperation with TSOs and ENTSO-E. ${ }^{4}$

As is illustrated in Figure 1.3, NRAs have gradually been made more independent of the industry and national governments. Initially, some countries like Germany did not see the need for an energy regulator but relied on combinations of self-regulation and competition authorities. The Second Package eventually put an end to such arrangements by requiring Member States to create national regulatory bodies that are independent of the electricity industry. The Third Package increased the independence of NRAs from national governments and also mandated the establishment of the Agency for the Cooperation of Energy Regulators (ACER). ${ }^{5}$ Figure 1.3 lists some of the NRAs' and ACER's tasks, which have clearly been increasing with each legislative package that has been adopted. We do not discuss them here, as they will be covered in the various chapters of this book.

Third are the more detailed market rules that have been developed through the process of creating EU network codes and guidelines. The first generation of network codes and guidelines were adopted after a lengthy co-creation process involving the European institutions, ENTSO-E, ACER and many stakeholders from across the electricity sector. This first generation consisted of eight legislative acts that entered into force between 2015 and the end of 2017. As we will refer to these network codes and guidelines throughout the book, Box 1.3 provides an introduction to the eight network codes and guidelines, their scope, and the related development, implementation and amendment processes. 


\section{BOX 1.3 THE FIRST GENERATION OF EU ELECTRICITY NETWORK CODES AND GUIDELINES}

The network codes and guidelines of the first generation can be subdivided into three groups or 'code families' as listed below.

- Market codes: the capacity allocation and congestion management guideline (CACM GL), published on 25 July 2015; the forward capacity allocation guideline (FCA GL), published on 27 September 2016; the electricity balancing guideline (EB GL), published on 23 November 2017.

- Connection network codes (CNCs): the network code on requirements for grid connection of generators (RfG NC), published on 14 April 2016; the network code on demand connection (DC NC), published on 18 August 2016; the network code on requirements for grid connection of high voltage direct current systems and direct current-connected power park modules (HVDC NC), published on 8 September 2016.

- Operation codes: the electricity transmission system operation guideline (SO GL), published on 25 August 2017; the electricity emergency and restoration network code (ER NC), published on 24 November 2017.

These are commonly referred to as 'the network codes', but not all of them are legally defined as network codes. Four of the eight are guidelines (CACM GL, FCA GL, EB GL and SO GL) and the other four are network codes (ER NC, RfG NC, DC NC and HVDC NC). Initially, all eight were planned to be developed as network codes, yet some became guidelines in the development process. In theory, network codes and guidelines can cover the same topics. In practice, however, it is observed that some topics lend themselves better to guidelines than to network codes and others vice versa.

Both similarities and differences between network codes and guidelines exist. Network codes and guidelines are similar in that they carry the same legal weight (both are Commission regulations and are legally binding), are directly applicable (they do not need to be transposed into national law) and are subject to the same formal adoption procedure ('old' comitology procedure). Network codes and guidelines differ from each other regarding their legal basis, the stakeholder involvement, their amendment process, topics and scope, and the adoption of further rules during the implementation phase. Indeed, the main difference is the work to be done during the implementation phase, which we explain in the following.

In general, network codes are more detailed than guidelines. Guidelines shift a larger share of the further development to the implementation phase, which can allow for more flexibility but can also slow down or complicate the overall process. Guidelines include processes whereby TSOs or Nominated Electricity Market Operators (NEMOs, see also Chapter 2) must develop so-called 'Terms and Conditions or Methodologies (TCM)'. TCMs are comprehensive (legal) texts that are often referred to as 'methodologies'. In most cases, methodologies have to be jointly developed by all TSOs or all NEMOs at the pan-European level or by the relevant TSOs/NEMOs at the regional or national levels. Depending on the scope of the methodologies, the Third Package foresaw their approval either by all NRAs (pan-European methodologies) or by the relevant subset of NRAs (regional and national 
methodologies). In certain cases, a decision is to be referred to ACER. ENTSO-E, ACER and the European Commission have monitoring, reporting and stakeholder involvement responsibilities related to methodologies. The implementation of the TCMs foreseen in the first generation of network codes and guidelines will continue until around 2025. We will refer to some of these methodologies in this book where relevant.

The regulatory guide in Annex 1A.1 provides detailed references to the relevant legislation.

Note: $\quad$ Our colleagues Hancher et al. (2020) published a research report which provides more details on the legal technicalities of the EU electricity network codes and guidelines.

For the first generation of network codes and guidelines, TSOs were placed in the position of drafting network codes through ENTSO-E with regulatory oversight. You may wonder why regulators have not been put in the position to develop these market rules. The typical answer given to this question in the European context is that the level of detail and technical complexity was such that the industry was asked to develop solutions that were then challenged by the regulators rather than vice versa. However, the perception has been that TSOs have not always developed solutions fast enough and that stakeholder involvement in the process has been insufficient. Following the Clean Energy Package, significant changes including shifts in roles and responsibilities have been introduced for both existing and future generations of EU network codes and guidelines, as is shown in Box 1.4.

\section{BOX 1.4 IMPLICATIONS OF THE EU CLEAN ENERGY PACKAGE FOR EU NETWORK CODES AND GUIDELINES}

In 2019, the adoption of the Clean Energy Package brought significant changes for both existing and future generations of EU network codes and guidelines. First, the development process saw a shift in roles and responsibilities. The strong role of ENTSO-E in drafting the network codes was reduced. The CEP also mandates the establishment of an EU DSO entity to involve distribution system operators (DSOs) in the network code and guideline drafting process. The role of ACER in the development phase is expected to increase. Another change concerns the time interval in which the European Commission is required to compile a priority list for new network codes.

Second, changes were introduced to the adoption process for both the TCM and new network codes and guidelines. Regarding TCMs, ACER now directly decides on the methodologies with a pan-European scale (former 'all NRA' decisions). Regarding network codes and guidelines, the Clean Energy Package distinguishes between the adoption of network codes and guidelines as implementing or delegated acts. Depending on the type of act, the European institutions and stakeholders have different rights and possibilities to intervene in the adoption process.

In other words, the story of EU network codes and guidelines as a way to push forward the market integration process in Europe continues. The scope of areas in which detailed market rules can be developed has increased and the process has been fine-tuned. How it will work in detail remains to be seen and can be reported in a future edition of this book. 
Note that we now have thousands of pages filled with detailed market rules, but they do not prescribe a standard market design that everybody needs to follow. In fact, the new rules simply reduce the degree of freedom that countries have in designing their markets. This is why it is difficult to read the European market rules. They do not explicitly explain the design; the resulting design is implicit. In this book, we will make it explicit.

\subsection{WHAT WERE THE TECHNICAL DRIVERS FOR CREATING A EUROPEAN POWER SYSTEM?}

In this section we will see that there are technical advantages of scale. ${ }^{6}$ For example, a larger power system is more stable as it has a higher level of inertia, which makes it easier for system operators to keep the lights on. Another technical advantage of integration in this context was the development of a solidarity mechanism between European countries that pre-dated the creation of markets. To better understand these technical issues, we will use a tandem bicycle analogy that is often used to explain power systems to non-engineers. Note that we are not exhaustive in our description and only refer to certain elements of this analogy. ${ }^{7}$

Imagine a tandem bicycle moving at a constant speed as illustrated in Figure 1.4. The task of the dark grey cyclists (power stations) is to generate the electrical energy that keeps the entire system going. The light grey figures (loads) are not generating any of this energy, but the aim of the overall system is to keep them moving nevertheless. The chain connecting all the elements in the system represents the electrical transmission network. To maintain the same velocity the chain must turn the wheels at a constant rate. In addition, constant physical tension is required in the upper part of the chain. These two features can be respectively translated into a need for a fixed constant frequency to guarantee a well-functioning system and a need for a fixed voltage level for grid connections in an electricity network.

To transmit the pedalling movement (energy) to the chain, different connections between the cyclists and the chain exist. A first type of dark grey cyclist (large thermal and nuclear power stations connected to the grid with transformers) have their pedals directly connected to the chain with one gear, which means they have to constantly pedal at the right speed and with the right amount of power. A second type of dark grey cyclist (e.g. hydropower stations with

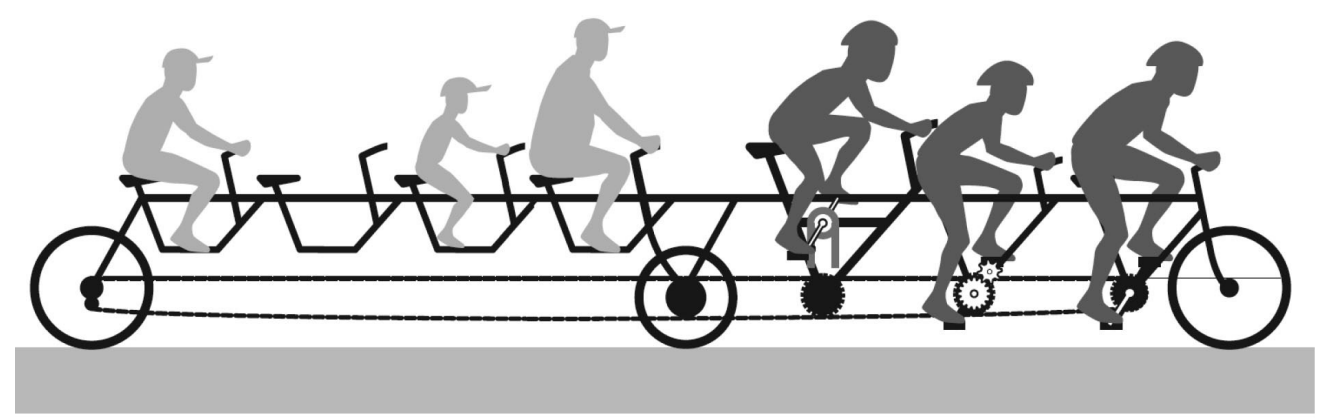

Note: Load is light grey and generation is dark grey.

Figure 1.4 A basic representation of the power system using a tandem bicycle 
their turbines connected to generators) may prefer to cycle more slowly and have their force transformed to the right speed with a gear system. A third type (e.g. wind turbines connected with a frequency inverter) is connected through a belt and a gear system, allowing them to pedal at varying speed. There are also different types of loads, but we will not explain them in detail here.

The complex task of power system management requires both the speed (frequency) and the tension of the chain (voltage level) to remain steady, even in the event of unexpected imbalances between load and generation. One of the technical advantages of scale is that the more synchronously connected rotating machines a power system has (dark grey cyclists types one and two), the more stable it is as it has a higher level of inertia. Inertia represents the ability of synchronously connected rotating machines to store and inject their kinetic energy into the system. Inertia slows down a frequency drop/spike immediately after a sudden mismatch between supply and demand (e.g. a power station outage or an unexpected change in the load connected to the network). If the system inertia is low, a small sudden difference between load and generation causes a high-frequency deviation. It is important to note that inertia only supports frequency in nearly instantaneous situations where an imbalance is caused by a sudden disconnection of large units or a nearly instantaneous change in production or load. Inertia does not support frequency under 'normal' imbalance conditions when the imbalance is caused by a prognosis error and resulting differences between production and consumption plans. System inertia is typically higher for larger synchronous power systems as the kinetic energy available and therefore the system's inertia increases with the number of generators and motors that are coupled to the grid.

However, system inertia can only slow down frequency deviations; it is not able to restore the power balance between generation and load. Therefore, some of the dark grey cyclists (power stations) do not pedal at full power. Instead, they conserve some of their energy to be able to provide extra or replacement force (reserves) when it is needed. TSOs, which are responsible for safeguarding system security within their control areas, must ensure that there are enough reserves to regulate frequency and respond to possible emergency situations. In a stand-alone system, such reserves must typically be large enough to cope with the most severe incident, which usually corresponds to a loss of the largest generator in one TSO's control area. A clear advantage of interconnecting control zones to form a large synchronous area is that reserves can be pooled and the relative importance of the most severe incident decreases as system size increases. Such solidarity schemes for reserve sharing in which each TSO can draw on the reserves in other TSOs' control zones whenever needed were implemented in synchronous areas long before markets were introduced. We will come back to the balancing mechanism that is in place today in Chapter 5. We will also come back to the technical requirements that different types of assets that are connected to the power system need to comply with in Chapter 6.

\subsection{WHAT DO WE KNOW ABOUT THE BENEFITS OF INTEGRATING ELECTRICITY MARKETS IN EUROPE?}

The initial focus of cross-border cooperation was on system stability as mentioned in the previous section and sharing of reserves as we will explain in the following. Sharing of reserves aimed at a more effective use of energy resources and optimal operation of electric power 
plants enabled by the interconnection of electricity networks. For example, by exporting electricity across borders, countries with large hydropower resources could prevent surplus production in their own country while at the same time allowing for savings in coal consumption in the neighbouring country. Similar qualitative reasoning is still valid in Europe today, as a single energy market is believed to take better advantage of the differences in industrial policy, available natural resources, weather conditions and load patterns across countries. For example, France is dominated by nuclear, Germany still has a large share of coal and Norway has significant hydro capacities, while the UK, Spain and Italy have higher relative shares of gas in their electricity mix. Countries with a large share of electrical heating such as France and Norway have larger differences between summer and winter consumption levels than countries with other heating sources. Time differences between countries can also be a source of differences in demand peaks. More recently, an important aspect of integration has been a better use of renewable resources due to uneven wind and solar conditions across Member States. Trade between European countries came only later, which was also due to the structure of the energy sector dominated by vertically integrated monopolies. However, already in the pre-liberalization period, long-term cross-border power purchase agreements with neighbouring utilities were sometimes preferred to authorizing the construction of new domestic power plants.

In the early 2000 s the new competitive environment was slowly manifesting itself as a result of the first two energy packages. At that time, questions were raised on how large the benefits of liberalization were, how these benefits could be reaped, and who could reap these benefits. The European Commission published several benchmarking reports to evaluate the implementation of electricity (and gas) directives in the early 2000s. These reports put forward indicators to check the health of particular markets. Competitive activity was measured with market development indicators related to concentration and new entries (e.g. the share of the three biggest generators, the share of the three biggest suppliers, the main retail supplier entrant type), switching estimates for different types of customers, price development (price convergence between Member States, price levels for different customer groups) and trade between Member States (the level of cross-border electricity exchange, use of interconnector capacity). None of the reports, however, included a quantification of the benefits of integrating national electricity markets to create an EU internal market for electricity. Only around 2012 did the European Commission task consultants with assessing the benefits of an integrated European electricity market. They concluded that the benefit was several billions of euros a year, an order of magnitude that was later confirmed by ACER. In its annual market monitoring report, ACER has been gradually improving its methodology to estimate these benefits and has also gone a long way in making the information that goes into the calculation more readily available. The ACER annual market monitoring report is a must-read for everybody reading this book. As it is highly technical, this book will give you the necessary background to be able to read it. ${ }^{8}$

More recently, the political developments around Brexit have led academics to estimate the potential cost of disruptions in electricity trade if the UK were to leave the European Union without a suitable trade deal. The electricity market in Great Britain, that is England, Scotland and Wales, is currently a single bidding zone, which is connected to Belgium, France and the Netherlands, and also to Northern Ireland and the Republic of Ireland. At the time of writing, uncertainty remains as to whether the political Brexit includes an 'Elecxit' (the UK leaving 
the EU internal energy market) and what longer-term consequences such a loss of a relatively small piece of the European electricity markets and the halting of interconnector expansion between Great Britain and neighbouring EU Member States would have. Academics have found that the 2030 cost to Britain of a hard electricity Brexit with little interconnector expansion and decoupled markets would amount to several hundreds of million euros a year. ${ }^{9}$

\subsection{CONCLUSION}

In this first chapter on why we started with electricity markets, we have answered three questions. First, what was the political process that led to electricity markets in Europe? The aim of creating a European internal energy market had been on the agenda of the European institutions since the 1980s. Over the period 1996 to 2019, four EU legislative energy packages were adopted that aimed to integrate and harmonize national electricity markets and mandated the creation of ENTSO-E and ACER to drive the process. EU network codes and guidelines were created that set out more detailed market rules. The Clean Energy Package introduced significant changes to the processes of developing, adopting, amending and implementing existing and future generations of network codes and guidelines.

Second, what were the technical drivers for creating a European power system? A clear advantage of larger power systems is their greater stability as they typically have larger numbers of synchronously connected rotating machines which increases the level of system inertia. Another technical advantage of scale is that the relative importance of the most severe incident decreases as system size increases and reserves to cope with such incidents can be pooled across TSO control zones. Such technical cooperation and reserve sharing among TSOs for mutual support through interconnections in case of emergencies pre-dated markets.

Third, what do we know about the benefits of integrating electricity markets in Europe? The qualitative benefits of exchanging electricity across borders to take advantage of the differences in generation mixes, weather conditions and load patterns have long been acknowledged by European countries. A more recent motivation has been to make better use of renewable resources due to uneven wind and solar conditions across Member States. The economics of market integration became clearer when information became available to assess the benefits. In 2013, an initial study found that the benefit of implementing an integrated EU electricity market was several billions of euros a year, an order of magnitude that was later confirmed by ACER. More recently, the potential cost to Great Britain of leaving the internal energy market as a part of the political Brexit has been estimated to be in the order of several hundred million euros a year by 2030 .

\section{NOTES}

1. It can be confusing to keep up with the varying terminology used for the European Single Market project, that is, common, internal and single market. The original treaties used the term 'common market' without providing a definition. Legal literature suggests that the concept of the common market went beyond the four freedoms and also included various policy areas such as agriculture, competition and state aid. Later, the term 'common market' was replaced with 'internal market' in the treaties, referring to an area without internal frontiers in which the free movements of goods, persons, services and capital are ensured. While the objectives remained the same, the procedures to adopt related legislation changed from unanimity (common market) to qualified majority voting 
(internal market). The term 'single market' can be considered an informal synonym of 'internal market'. Note that in some languages, only one word exists (e.g. 'Binnenmarkt' in German).

2. Hancher (2002) discusses the successes and failures of the First Electricity Directive of 1996 in introducing a competitive environment in national electricity sectors. Vasconcelos (2005), the founder of the Council for European Energy Regulators (CEER) in 2000, explains that the First Energy Directive provided little guidance as regards cross-border energy trade, the development of regional markets, interaction with non-EU markets, the development of interconnectors, the supra-national integration of energy markets and so on. Hence, a 'regulatory gap' between national markets and the EU internal energy market emerged. He elaborates on how Regulation (EC) No 1228/2003, which we will discuss in Chapter 2, represented the Commission's attempt to close the 'regulatory gap', which was shown to be not possible on a voluntary basis.

3. CEER (2016) provides an overview and explanation of the different unbundling models applied across European Member States. TSOs also continue to change, as is seen in the example of the Greek TSO. ADMIE moved from the Independent Transmission Operator model to the Ownership Unbundling model as a consequence of changes in the ownership and share structure (CEER 2019).

4. We do not cover the EU DSO entity in this book as there are still many open issues at the time of writing. In the future, the EU DSO entity is expected to play a significant role for example as regards the preparation and implementation of new network codes, where relevant for distribution networks. We might therefore include its tasks and responsibilities in a future edition of this book.

5. Glachant et al. (2008) analyse the institutional mechanisms of the German self-regulation arrangement that lasted from 1998 to 2005. Pototschnig (2019) provides a comprehensive overview of developments from the creation of ACER to its future as foreseen in the Clean Energy Package. Jones (2016) provides a full overview of the Third Energy Package, including the topics discussed here of common electricity wholesale markets, the unbundling of TSOs, NRAs and the coming into existence of ACER, and the regulation of cross-border electricity exchanges.

6. Many of the technical, economic and regulatory fundamentals we touch on in this book are discussed in depth in Pérez-Arriaga (2013), which is a must-read for anybody entering the sector or wanting to refresh their knowledge of some of the basic concepts the electricity sector deals with on a daily basis.

7. We do not know who came up with this analogy, but were inspired by Söder (2002) and Fassbinder and De Wachter (2005). Many thanks to our colleague Daniela Bernardo, who produced the drawing in Figure 1.4, which is an enhanced version of a drawing in Söder (2002).

8. DG TREN (2001) was the first of four benchmarking reports published by the Commission of the European Communities. Booz \& Company (2013) is the consultancy study. ACER and CEER (2019) is the annual market monitoring report. Newbery et al. (2016) provide an academic discussion of the methodology that is used in these reports.

9. This paragraph is based on the work of Geske et al. (2020), who calculate the estimated 2030 cost of Great Britain leaving the EU internal market for electricity based on a microeconomic model of decoupled markets between Great Britain and France. Newbery (2020) discusses their results in a brief review for Nature Energy.

\section{REFERENCES}

ACER and CEER (2019), 'Annual Report on the Results of Monitoring the Internal Electricity and Natural Gas Markets in 2018 - Electricity Wholesale Markets Volume'.

Booz \& Company (2013), 'Benefits of an Integrated European Energy Market', Final Report prepared for Directorate-General Energy European Commission.

CEER (2016), 'Status Review on the Implementation of Transmission System Operators' Unbundling Provisions of the 3rd Energy Package', CEER Status Review Ref: C15-LTF-43-04.

CEER (2019), 'Implementation of TSO and DSO Unbundling Provisions - Update and Clean Energy Package Outlook', CEER Status Review Ref: C18-LAC-02-08.

Council (1986), 'Council Resolution of 16 September 1986 Concerning New Community Energy Policy Objectives for 1995 and Convergence of the Policies of the Member States (86/C 241/01)'. 
DG TREN (2001), 'First benchmarking report on the implementation of the internal electricity and gas market. SEC (2001) 1957', Commission Staff Working Paper.

EC (1988), 'The internal energy market', Commission Working Document COM(88) 238 Final.

Fassbinder, S. and B. De Wachter (2005), 'The electrical system as a tandem bicycle', accessed at www .gonder.org.tr/wp-content/uploads/2015/04/ElectricityTandem.pdf\%0A\%0A.

Geske, J., R. Green and I. Staffell (2020), 'Elecxit: The cost of bilaterally uncoupling British-EU electricity trade', Energy Economics, 85, 104599.

Glachant, J.-M., U. Dubois and Y. Perez (2008), 'Deregulating with no regulator: Is the German electricity transmission regime institutionally correct?', Energy Policy, 36 (5), 1600-10.

Hancher, L. (2002), 'Slow and not so sure: Europe's long march to electricity market liberalization', Electricity Journal, 10 (9), 92-101.

Hancher, L., A.-M. Kehoe and J.Rumpf (2020), 'The EU Electricity Network Codes and Guidelines: A Legal Perspective', Research Report, European University Institute.

Jones, C. (ed.) (2016), EU Energy Law Volume I: The Internal Energy Market, 4th ed., Deventer, Netherlands and Leuven, Belgium: Claeys \& Casteels.

Newbery, D. M. (2020), 'The cost of uncoupling', Nature Energy, 5 (3), 187-8.

Newbery, D., G. Strbac and I. Viehoff (2016), 'The benefits of integrating European electricity markets', Energy Policy, 94, 253-63.

Pérez-Arriaga, I. J. (ed.) (2013), Regulation of the Power Sector, Springer-Verlag London.

Pototschnig, A. (2019), 'The ACER experience', in S. Nies (ed.), The European Energy Transition: Actors, Factors, Sectors, Deventer, Netherlands and Leuven, Belgium: Claeys \& Casteels, pp. 175-211.

Söder, L. (2002), 'Explaining power system operation to non-engineers', IEEE Power Engineering Review, 22 (4), 25-7.

Vasconcelos, J. (2005), 'Towards the internal energy market, how to bridge a regulatory gap and build a regulatory framework', European Review of Energy Markets, 1 (1). 


\section{A.1 ANNEX: REGULATORY GUIDE}

\section{Table 1A.1 Regulatory guide}

\author{
Section of this chapter, topic and relevant regulation \\ Section 1.1 \\ The aim to create a common market to eliminate trade barriers \\ between Member States dates back to the founding Treaty of \\ Rome in 1957.
}

The Single European Act of 1986 required the adoption of measures with the aim of establishing an internal market by 31 December 1992.

The Council (1986) adopted energy objectives for the European Community.

In 1988, the Commission of the European Communities published the first document on the internal energy market, which assessed that there were still considerable barriers to trade in energy products within the Community.

Directive 96/92/EC kicked off the liberalization process by introducing a distinction between the regulated part of the sector and competitive parts.
Relevant articles

Art. 2 of the Treaty of Rome states that 'The Community shall have as its task, by establishing a common market and progressively approximating the economic policies of Member States, to promote throughout the Community a harmonious development of economic activities, a continuous and balanced expansion, an increase in stability, an accelerated raising of the standard of living and closer relations between the States belonging to it.'

The Treaty includes, among many other things, provisions on the free movement of goods (Title I) and the free movement of persons, services and capital (Title III).

Art. 13 of the Single European Act states that '... the Community shall adopt measures with the aim of progressively establishing the internal market over a period expiring on 31 December 1992 ... The internal market shall comprise an area without internal frontiers in which the free movement of goods, persons, services and capital is ensured ...'

In the Council Resolution of 16 September 1986, the Council of the European Communities ' ... 5. considers that the energy policy of the Community and of the Member States must endeavour to achieve the following horizontal objectives: ... (d) greater integration, free from barriers to trade, of the internal energy market with a view to improving security of supply, reducing costs and improving economic competitiveness.' The Commission Working Document COM(88) 238 final on the internal energy market of 2 May 1988 states in its Part Two on the suggested priorities regarding the obstacles related to the establishment of a single energy market that the 'barriers are very diverse in type and significance... Most of them are the end-product of domestic rules and regulations originating in an often distant past predating European ideas: this applies for example to all the potential obstacles arising from purely domestic monopolies. ...'

As illustrations, recital 22 of Directive 96/92/EC states that it is ... necessary to establish common rules for the production of electricity and the operation of electricity transmission and distribution systems'; and recital 30 states that 'in order to ensure transparency and non-discrimination, the transmission function of vertically integrated undertakings should be operated independently from the other activities.' 
Section of this chapter, topic and relevant regulation

However, Directive 96/92/EC left a large margin of choice for the Member States as to how to introduce more competition into their electricity markets.

The First Package only required management and accounting unbundling.

The Second Package required transmission and distribution companies to apply legal unbundling.

The Third Package required TSOs to be certified by the competent NRA under one of three unbundling models.
Relevant articles

Art. 7(5) and Art. 11(2) state for TSOs and DSOs respectively that they shall not 'discriminate between system users or classes of system users, particularly in favour of [their] subsidiaries or shareholders.'

Recital 11 of Directive 96/92/EC states that 'in accordance with the principle of subsidiarity, general principles providing for a framework must be established at Community level, but their detailed implementation should be left to Member States, thus allowing each Member State to choose the regime which corresponds best to its particular situation'; and recital 12 states further that ' whatever the nature of the prevailing market organisation, access to the system must be open in accordance with this Directive and must lead to equivalent economic results in the States and hence to a directly comparable level of opening-up of markets and to a directly comparable degree of access to electricity markets.'

Art. 14(3) of Directive 96/92/EC states that 'Integrated electricity undertakings shall, in their internal accounting, keep separate accounts for their generation, transmission and distribution activities, and, where appropriate, consolidated accounts for other, non-electricity activities, as they would be required to do if the activities in question were carried out by separate undertakings, with a view to avoiding discrimination, cross-subsidization and distortion of competition.'

Art. 10 and Art. 15 of Directive 2003/54/EC state for TSOs and DSOs respectively that 'Where the [TSO,DSO] is part of a vertically integrated undertaking, it shall be independent at least in terms of its legal form, organisation and decision making from other activities not relating to [transmission, distribution]. These rules shall not create an obligation to separate the ownership of assets of the [TSO, DSO] from the vertically integrated undertaking.'

Art. 9 of Directive 2009/72/EC specifies rules on the unbundling of transmission systems and TSOs. While Art. 9(1) implies that the preferred model is ownership unbundling, Art. 9(8) gives Member States the possibility not to apply Art. 9(1) where 'on 3 September 2009, the transmission system belongs to a vertically integrated undertaking'. In such cases, Member States are given a choice between ownership unbundling and setting up a system operator or transmission operator which is independent from supply and generation interests.

Art. 10 of Directive 2009/72/EC lays down the rules for the designation and certification of transmission system operators. 


\begin{tabular}{ll}
\hline Section of this chapter, topic and relevant regulation & Relevant articles \\
\hline The Third Package also required all the TSOs to create and & Art. 4 of Regulation (EC) No 714/2009 requires all TSOs \\
cooperate via ENTSO-E. & to 'cooperate at Community level through the ENTSO for \\
& $\begin{array}{l}\text { Electricity, in order to promote the completion and functioning } \\
\text { of the internal market in electricity and cross-border trade }\end{array}$ \\
& $\begin{array}{l}\text { and to ensure the optimal management, coordinated operation } \\
\text { and sound technical evolution of the European electricity } \\
\text { transmission network.' }\end{array}$
\end{tabular}

The selection of TSO and ENTSO-E tasks according to the First, Second, Third and Clean Energy Package listed in Figure 1.2 .

The Clean Energy Package also requires the establishment of an entity of distribution system operators in the Union (EU DSO entity).

The Second Package required Member States to create national regulatory bodies that are independent of the electricity industry.

The Third Package increased the independence of NRAs from national governments and mandated the establishment of ACER.

The selection of NRA and ACER tasks according to the Second, Third and Clean Energy Package listed in Figure 1.3.
Art. 5 of the same Regulation lays down the process of establishing ENTSO-E.

The tasks of TSOs described are laid out in Art. 7 and Art. 8 of Directive 96/92/EC and Art. 9 and Art. 11 of Directive 2003/54/EC.

The tasks of ENTSO-E described are laid out in Art. 8 of Regulation (EC) No 714/2009 and Art. 30 of Regulation (EU) 2019/943.

Arts. 52 to 57 of Regulation (EU) 2019/943 lay down provisions for the EU DSO entity.

Art. 23(1) of Directive 2003/54/EC states that 'Member States shall designate one or more competent bodies with the function of regulatory authorities. These authorities shall be wholly independent from the interests of the electricity industry. They shall ... at least be responsible for ensuring non-discrimination, effective competition and the efficient functioning of the market ...'

Art. 35 of Directive 2009/72/EC lays out the rules on the designation and independence of regulatory authorities. Art. 35(1) says that 'Each Member State shall designate a single national regulatory authority at national level.' Art. 35(5.a) specifies that 'In order to protect the independence of the regulatory authority, Member States shall in particular ensure that: (a) the regulatory authority can take autonomous decisions, independently from any political body, and has separate annual budget allocations ...'

Regulation (EC) No 713/2009 establishes ACER and puts forward the following motivation in recital 3: 'it is widely recognised by the sector ... that voluntary cooperation between national regulatory authorities should now take place within a Community structure with clear competences and with the power to adopt individual regulatory decisions in a number of specific cases.'

The tasks of NRAs described are laid out in Art. 23 of Directive 2003/54/EC.

The tasks of ACER described are laid out in Chapter II, Arts. 5-11 of Regulation (EC) No 713/2009 and Arts. 3-15 of Regulation (EU) 2019/942. 


Section of this chapter, topic and relevant regulation
Network codes and guidelines are adopted in a lengthy
co-creation process involving the European institutions,
ENTSO-E, ACER and many stakeholders from across the
electricity sector.
Network codes and guidelines carry the same legal weight,
are directly applicable, and are subject to the same adoption
procedure.
Network codes and guidelines differ from each other with
regard to their legal basis (Art. 6 of Regulation (EC) No
$714 / 2009$ for network codes and Art. 8 of the same regulation
for guidelines), development process, amendment process and
implementation process.

implementation process.
Relevant articles

Development of network codes: Under the Third Package, the network code development process includes multiple steps as specified in Art. 6 of Regulation (EC) No 714/2009 and simplified in the following.

First, after having consulted ACER, ENTSO-E and other relevant stakeholders, the European Commission establishes an annual priority list for possible network code areas. Second, at the request of the European Commission, ACER develops a non-binding framework guideline setting out principles for the development of such network codes and consults with ENTSO-E and other relevant stakeholders. If the European Commission considers that the framework guideline does not contribute to non-discrimination, effective competition and the efficient functioning of the market, it may request ACER to review and resubmit the framework guideline. If ACER fails to submit a framework guideline, the European Commission itself elaborates the framework guideline. Third, the European Commission requests ENTSO-E to develop and submit to ACER a network code based on the ACER framework guideline. Fourth, ACER consults relevant stakeholders and provides ENTSO-E with a reasoned opinion on the network code. Fifth, ENTSO-E may amend the network code in the light of the ACER opinion and resubmit it to ACER. Sixth, when satisfied that the network code is in line with the framework guideline, ACER submits the network code to the European Commission and may recommend its adoption. Adoption of network codes is in the hands of the European Commission. The European Commission provides reasons in the case where it does not adopt the network code. Where ENTSO-E has failed to develop the network code, the European Commission may request ACER to prepare a draft network code. On its own initiative or on the failure of ENTSO-E (ACER) to develop a (draft) network code or on recommendation by ACER, the European Commission may also adopt one or more network codes. Where the European Commission proposes to adopt a network code on its own initiative, it consults ACER, ENTSO-E and the relevant stakeholders.

Amendment of network codes: Amendments to network codes under the Third Package may be proposed to ACER by any person who is likely to have an interest in that network code, including ENTSO-E, TSOs, system users and consumers. ACER may also propose amendments on its own initiative. ACER consults stakeholders and may make a reasoned proposal for amendment to the European Commission. Taking account of the ACER proposals, the European Commission may adopt amendments to any network code. 
Section of this chapter, topic and relevant regulation

In theory, network codes and guidelines can cover the same topics.

Depending on the scope of the respective methodology, the Third Package foresaw its approval either by all NRAs or the relevant subset of NRAs.

Under the Third Package, in certain cases a decision is to be referred to ACER.
Relevant articles

Development and amendment of guidelines: Under the Third Package, the procedural requirements for guidelines in accordance with Art. 18 of Regulation (EC) No 714/2009 are less far-reaching. Art. 18(3) states that, where appropriate, the Commission can also develop guidelines for areas that are covered by network codes according to Art. 8(6). Art. 18(3) states further that the Commission shall consult the Agency and ENTSO-E for this purpose. When adopting or amending guidelines, the Commission must, among other things, ensure that the guideline provides the minimum degree of harmonization necessary to achieve the goals of the regulation and does not go beyond what is necessary for this purpose. Adoption of network codes and guidelines: Under the Third Package and in accordance with Art. 23 of Regulation (EC) No 714/2009, network codes and guidelines were adopted as implementing acts under the 'old' comitology procedure, following the regulatory procedure with scrutiny.

Implementation of network codes and guidelines: As is described in Box 1.3 of Section 1.1, guidelines include processes whereby TSOs or NEMOs must develop so-called 'Terms and Conditions or Methodologies' in the implementation phase.

Under the Third Package, Art. 18(6) of Regulation (EC) No $714 / 2009$ states that 'Where appropriate, Guidelines providing the minimum degree of harmonisation required to achieve the aim of this Regulation shall also specify: ... (d) details of the areas listed in Article 8(6).'Art. 8(6) of the same regulation lists the areas that network codes shall cover, taking into account, if appropriate, regional specificities.

Under the Clean Energy Package, in accordance with Art. 61(2) of Regulation (EU) 2019/943, the 'Commission is empowered to adopt guidelines in the areas where such acts could also be developed under the network code procedure pursuant to Article 59(1) and (2). Those guidelines shall be adopted in the form of delegated or implementing acts, depending on the relevant empowerment provided for in this Regulation.'

As is set out in Art. 9 of the CACM GL, Art. 4 of the FCA GL, Art. 5 of the EB GL and Art. 6 of the SO GL.

In accordance with Art. 8(1) of Regulation (EC) No 713/2009, in certain cases a decision should be referred to ACER, namely (a) when the competent NRAs are not able to reach an agreement within a period of six months from the point in time when the case was referred to the last of those NRAs or (b) on a joint request from the competent NRAs. 


Section of this chapter, topic and relevant regulation

ENTSO-E, ACER and the European Commission have monitoring, reporting and stakeholder involvement responsibilities related to methodologies.

For the first generation of network codes and guidelines, through ENTSO-E, TSOs were placed in the position of drafting network codes with regulatory oversight.

Following the CEP, the strong role of ENTSO-E in drafting the network codes was reduced.

The CEP also mandates the establishment of an EU DSO entity to involve DSOs in the network code and guideline drafting process.
Relevant articles

Under the Third Package, relevant provisions, apart from the dedicated articles on network codes and guidelines, include Regulation (EC) No 714/2009: Art. 8 on the tasks of ENTSO-E, Art. 9 on monitoring by ACER and Art. 10 on consultations; and Regulation (EC) No 713/2009: Art. 6 on the tasks of ACER as regards the cooperation of TSOs, Art. 8 on the tasks of ACER as regards terms and conditions for access to and the operational security of cross-border infrastructure, Art. 10 on consultations and transparency, and Art. 11 on monitoring and reporting on the electricity and natural gas sectors.

Under the Clean Energy Package, relevant provisions, apart from the dedicated articles on network codes and guidelines, include Regulation (EU) 2019/943: Art. 30 on the tasks of ENTSO-E, Art. 31 on consultations, Art. 32 on monitoring by ACER, Art. 41 on transparency, Art. 56 on consultations in the network code development process, Art. 69 on Commission reviews and reports; Regulation (EU) 2019/942 Art. 5 on the tasks of ACER as regards the development and implementation of network codes and guidelines, Art. 8 on the tasks of ACER as regards nominated electricity market operators, Art. 24 on consultations, transparency and procedural safeguards, and Art. 15 on monitoring and reporting on the electricity and natural gas sectors.

Art. 8(1) of Regulation (EC) No 714/2009 states that 'The ENTSO for Electricity shall elaborate network codes in the areas referred to in paragraph 6 of this Article upon a request addressed to it by the Commission ....

Art. 59(10) of Regulation (EU) 2019/943 specifies that in the third step of the network code development process described above, ENTSO-E now drafts the network code based on an ACER framework guideline guided by a drafting committee that consists of representatives of ACER, ENTSO-E, where appropriate the EU DSO entity and NEMOs, and a limited number of relevant stakeholders.

Art. 52(1) of Regulation (EU) 2019/943 states that 'Distribution system operators shall cooperate at Union level through the EU DSO entity, in order to promote the completion and functioning of the internal market for electricity, and to promote optimal management and a coordinated operation of distribution and transmission systems. ...' Arts. 52-57 lay down rules on distribution system operation, including the establishment of the EU DSO entity, relevant principal rules and procedures, and the tasks of the EU DSO entity. 
Section of this chapter, topic and relevant regulation

With the adoption of the CEP, the role of ACER in the development phase is expected to increase.

Another change concerns the time interval in which the European Commission is required to compile a priority list for new network codes.

ACER now directly decides on the methodologies with a pan-European scale.
Relevant articles

Art. 59(3) of the same regulation states that '... If the subject matter of the network code is directly related to the operation of the distribution system and not primarily relevant to the transmission system, the Commission may require the EU DSO entity, in cooperation with the ENTSO for Electricity, to convene a drafting committee and submit a proposal for a network code to ACER.'

In the network code development process following the Third Package, as laid down in Art. 6(6-9) of Regulation (EC) No $714 / 2009$ and as described above, ACER is required to provide a reasoned opinion on the network code submitted to it by ENTSO-E, after which ENTSO-E may amend the network code in the light of this opinion and resubmit it to the Agency. Under the Clean Energy Package, Art. 59(11) of Regulation (EU) 2019/943 states that, in the fourth step of the network code development process described above, ACER will henceforth directly revise and consolidate the network code and submit the final product to the European Commission: 'ACER shall revise the proposed network code ... and, submit the revised network code to the Commission within six months of receipt of the proposal.'ACER must take into account the views provided by all the parties involved in the drafting of the proposal and consult the relevant stakeholders on the version to be submitted to the Commission. Details are also provided in Art. 5(1.c) of Regulation (EU) 2019/942.

Under the Third Package, Art. 6(1) of Regulation (EC) No $714 / 2009$ states that 'The Commission shall, after consulting the Agency, the ENTSO for Electricity and the other relevant stakeholders, establish an annual priority list identifying the areas set out in Article 8(6) to be included in the development of network codes.'

Under the Clean Energy Package, Art. 59(3) of Regulation (EU) 2019/943 states that 'The Commission shall, after consulting ACER, the ENTSO for Electricity, the EU DSO entity and the other relevant stakeholders, establish a priority list every three years, identifying the areas ... to be included in the development of network codes.'

Under the Third Package and in accordance with Art. 8(1), decisions are only referred to ACER when (a) the competent NRAs are not able to reach an agreement within a period of six months from the point in time when the case was referred to the last of those NRAs or (b) on a joint request from the competent NRAs. 
Section of this chapter, topic and relevant regulation

The Clean Energy Package distinguishes between the adoption of network codes and guidelines as implementing or delegated acts. Depending on the type of act, the European institutions and stakeholders have different rights and possibilities to intervene in the adoption process.
Relevant articles

Under the Clean Energy Package, proposals for common

'Terms and Conditions or Methodologies' for the implementation of network codes and guidelines which require the approval of all regulatory authorities shall be submitted to ACER for revision and approval in accordance with Art. 5(2) of Regulation (EU) 2019/942.

Under the Third Package and in accordance with Art. 23 of Regulation (EC) No 714/2009, network codes and guidelines were adopted as implementing acts under the 'old' comitology procedure, following the regulatory procedure with scrutiny. The Clean Energy Package distinguishes between the adoption of network codes and guidelines as implementing or delegated acts in accordance with Art. 58 of Regulation (EU) 2019/943. Network Codes as implementing acts: Art. 59(1) of Regulation (EU) 2019/943 lists the areas in which the Commission is empowered to adopt network codes as implementing acts. Adoption of network codes as implementing acts is divided into two main phases. During the pre-comitology process, the European Commission undertakes legal and impact assessment of the implementing act, among other things. During the comitology phase, the Commission submits draft implementing acts to a committee composed of Member State representatives. The committee votes on the draft with three possible outcomes. In the first case, a qualified majority of Member States votes in favour of the act resulting in an obligation on the European Commission to adopt the act. In the second case, a qualified majority votes against the act, which prohibits the European Commission from adopting it. In the third case, no qualified majority for or against exists, which means the European Commission may adopt the draft.

The CEP empowers the European Commission to adopt new network codes as implementing acts in the areas of: (existing, covered by SO GL) network security and reliability rules; (existing, covered by CACM GL and FCA GL) capacity-allocation and congestion-management rules; (existing, covered by EB GL) rules on trading related to the technical and operational provision of network access services and system balancing; (new) rules for the non-discriminatory transparent provision of non-frequency ancillary services; and (new) rules on demand response, including aggregation, energy storage and demand curtailment. 
Section of this chapter, topic and relevant regulation
Relevant articles

Network codes as delegated acts: Art. 59(2) of Regulation

(EU) 2019/943 lists the areas in which the Commission is empowered to adopt network codes as delegated acts. Adoption as a delegated act can be seen as a fast-track adoption process, as comitology committees do not exist. The European Commission prepares and adopts delegated acts after consulting national expert groups composed of representatives from each Member State. Citizens and other stakeholders can provide feedback on the draft of the delegated act. The European Commission then presents its draft delegated act simultaneously to both the European Parliament and the Council without consulting a committee. In the case that the Parliament and Council do not formulate any objections, the delegated act enters into force.

The CEP empowers the Commission to adopt new network codes as delegated acts in the areas of: (existing, covered by RfG NC, DC NC, HVDC NC) network connection rules; (existing, covered by ER NC) operational emergency and restoration procedures in an emergency; (covered partly by SO GL and Transparency Regulation (EU) No 543/2013) data exchange, settlement and transparency rules; third-party access rules (set out in Regulation (EC) No 714/2009 as an area but not yet covered by a network code); and (new) sector-specific rules for cyber security aspects of cross-border electricity flows.

Guidelines: In accordance with Art. 61(2) of Regulation (EU) 2019/943, the Commission can adopt guidelines in the network code areas in the form of delegated or implementing acts. Art. 61 of the same regulation specifies that the adoption and amendment procedure for guidelines now includes the obligation for the European Commission to consult ACER, ENTSO-E, the EU DSO entity and, where relevant, other stakeholders. 